\title{
FOETOMATERNAL OUTCOME IN CASES OF PREMATURE RUPTURE OF MEMBRANE (PROM) AT TERM: AN EXPERIENCE IN OUR INSTITUTE
}

\author{
Badam Rajani Kumari ${ }^{1}$, Chodavarapu Sailaja², Prasad Usha ${ }^{3}$
}

${ }^{1}$ Assistant Professor, Department of Obstetrics and Gynaecology, Andhra Medical College, Visakhapatnam, Andhra Pradesh. ${ }^{2}$ Assistant Professor, Department of Obstetrics and Gynaecology, Andhra Medical College, Visakhapatnam, Andhra Pradesh. ${ }_{3}^{3}$ Assistant Professor, Department of Obstetrics and Gynaecology, Andhra Medical College, Visakhapatnam, Andhra Pradesh.

\section{ABSTRACT}

\section{BACKGROUND}

Prelabour Rupture of Membranes (PROM) remains a day-to-day problem for each and every obstetrician. Despite extensive research, most aspects of PROM remain unknown and as prevention of PROM is difficult one has to concentrate more on management of PROM to reduce its complications.

\section{AIM OF THE STUDY}

This study was aimed to understand incidence, causes, neonatal morbidity and mortality, maternal morbidity and mortality in cases of PROM and its effective management.

\section{MATERIAL AND METHODS}

A prospective hospital-based study was undertaken on 100 cases with PROM at term between 37 and 40 weeks in the Department of Obstetrics and Gynaecology during the period from April 2015 to March 2016. After delivery, APGAR scores at 1 minute were noted and those babies needing NICU admission were recorded. The causes for maternal morbidity were noted and results tabulated.

\section{RESULTS}

The incidence of PROM was highest in age group 20-29 years [49\%] followed by age group less than 20 years [38\%] and 13 cases [13\%] in the age group above 30 years. In primigravida, the incidence was highest [58\%]. PROM cases were higher in the below poverty line group [76\%]. In 33\%, no risk factors were identified. Maximum number of cases delivered within 7-12 hours of PROM [69\%]. Most of the women delivered vaginally either spontaneously or after induction with misoprostol in $66 \%$ of cases. 88 babies [88\%] had Apgar score 8-10. Most common complication in the mother was fever [12\%] and in the newborn was septicaemia [6\%].

\section{CONCLUSION}

PROM is associated with increased maternal and perinatal complications especially when duration of PROM is more than 12 hours. Identifying known risk factors, proper counseling, and prompt treatment of infections either UTI or vaginal is mandatory.

\section{KEYWORDS}

PROM, Term, Sepsis, UTI, Antibiotics, Maternal, and Perinatal Complications.

HOW TO CITE THIS ARTICLE: Kumari BR, Sailaja C, Usha P. Foetomaternal outcome in cases of premature rupture of membrane (prom) at term: an experience in our institute. J. Evolution Med. Dent. Sci. 2016;5(64):4508-4511, D0I: $10.14260 /$ jemds/2016/1029

\section{INTRODUCTION}

Prelabour rupture of membranes still features in the majority of causes of neonatal morbidity and mortality and accounts for a great number of admissions to neonatal intensive care unit.[1,2] At term, infection remains the most serious complication associated with PROM for the mother and the baby. The risk of chorioamnionitis with term PROM has been reported to be less than $10 \%$ and to increase to $40 \%$ after 24 hours of PROM.[3] The aetiology of PROM is multifactorial; enzymes, nutritional, mechanical factors, chorioamniotic membrane phospholipid content, collagen disruption by amniotic cells cytokines induced by foetal signals, bacterial phospholipase and collagenases, all play major and interrelated role.[4]

Financial or Other, Competing Interest: None.

Submission 02-07-2016, Peer Review 26-07-2016,

Acceptance 02-08-2016, Published 09-08-2016.

Corresponding Author:

Dr. Prasad Usha,

\#Q. No 49-3-3, Lalithanagar,

Visakhapatnam-530016,

Andhra Pradesh.

E-mail: ushaprasad411@gmail.com

DOI: $10.14260 /$ jemds/2016/1029

\section{MATERIAL AND METHODS}

A prospective hospital-based study was undertaken on 100 cases with PROM at term between 37 and 40 weeks in the Department of Obstetrics and Gynaecology during the period from April 2015 to March 2016. The number of deliveries during this period was 8,328 . Those with premature rupture of membranes before 37 weeks, those with congenital anomalies of foetus, intrauterine death, multiple pregnancies, post caesarean pregnancies, and associated medical complications in pregnancy were excluded from the study.

A sterile speculum examination without using antiseptic was done and the presence of amniotic fluid was noted and the fluid examined under microscope for ferning. High vaginal swab was taken and sent for culture and sensitivity. The women were admitted and a detailed history was taken and clinical examination and laboratory investigations were done. Duration of PROM was noted. All cases were given prophylactic IV antibiotics, mostly cephalosporins. Mode of delivery was planned according to other obstetric factors. After delivery, APGAR scores at 1 minute were noted and those babies needing NICU admission were recorded. Maternal morbidity such as fever, wound infection, sepsis, etc. was noted. 


\section{RESULTS}

The incidence of PROM in our study was $1.2 \%$. The incidence of PROM was highest in age group 20-29 years 49 cases [49\%], followed by age group less than 20 years 38 cases [38\%], and 13 cases [13\%] in the age group above 30 years. In primigravida, the incidence was highest 58 cases [58\%]. PROM cases were higher in the Below Poverty Line [BPL] group 76 cases [76\%] [Table 1]. In 33 cases [33\%], no risk factors were identified, previous history of $\mathrm{D}$ and $\mathrm{C}$ was present in 12 cases [12\%], cervical incompetence in 11 cases [11\%], h/o previous preterm in 9 cases [9\%], h/o previous PROM in 8 cases [8\%], recent coitus in 7 cases [7\%], malpresentations in 6 cases [6\%], UTI in 6 cases [6\%], hydramnios in 4 cases [4\%], and twins in 4 cases [4\%]. [Table 2].

Maximum number of cases delivered between 7-12 hours of PROM, the number being 43 [43\%]. The number of cases delivering within 6 hours was 26 [26\%], 21 [21\%] women delivered between 13-18 hours. The number of cases who delivered between 19-24 hours was 18 [18\%]. In 12 cases [12\%], delivery occurred after 24 hours [Table 3]. Most of the women delivered vaginally either spontaneously or after induction with misoprostol in 66 cases [66\%]. Forceps was applied in 13 cases [13\%]. Elective LSCS and emergency LSCS was done in 7 [7\%] and 14 [14\%] cases respectively. [Table 4].

There was 2 babies [2\%] with Apgar score 0-4, 10 babies [10\%] with Apgar score 5-8 and 88 babies [88\%] with Apgar score 8-10. The most common cause for NICU admission was septicaemia 6 cases [6\%] [Table 5]. Most common complication in the mother was fever in 12 cases [12\%] followed by wound infection in 8 cases [8\%]. Septicaemia shock was seen in 2 cases [2\%] and abruption in 4 cases [4\%] [Table 6]. In 67 cases [67\%], culture was sterile and the most common bacteria isolated was Staphylococcus in 20 cases [20\%] [Table 7].

\begin{tabular}{|c|c|c|}
\hline Age & No. of Cases & Percentage \\
$<20$ yrs. & 38 & $38 \%$ \\
$20-29$ yrs. & 49 & $49 \%$ \\
>30 yrs. & 13 & $13 \%$ \\
\hline Parity & \\
Primi & 58 & $58 \%$ \\
$2^{\text {nd }}$ Gravida & 16 & $16 \%$ \\
3rd Gravid & 26 & $26 \%$ \\
\hline Socioeconomic Status & 76 & $76 \%$ \\
BPL & 24 & $24 \%$ \\
APL & \multicolumn{2}{|c|}{ Table 1: Demographic Factors } \\
\hline \multicolumn{2}{|c}{} \\
\hline
\end{tabular}

\begin{tabular}{|c|c|c|}
\hline Risk Factor & No. of Cases & Percentage \\
\hline Cervical incompetence & 11 & $11 \%$ \\
\hline Malpresentations & 6 & $6 \%$ \\
\hline H/o previous PROM & 8 & $8 \%$ \\
\hline H/o previous Preterm & 9 & $9 \%$ \\
\hline Hydramnios & 4 & $4 \%$ \\
\hline UTI & 6 & $6 \%$ \\
\hline Twins & 4 & $4 \%$ \\
\hline Previous D and C & 12 & $12 \%$ \\
\hline Recent coitus & 7 & $7 \%$ \\
\hline No risk factors & 33 & $33 \%$ \\
\hline Total & $\mathbf{1 0 0}$ & $\mathbf{1 0 0} \%$ \\
\hline Table 2: Risk Factors Associated with PROM \\
\hline
\end{tabular}

\begin{tabular}{|c|c|c|}
\hline Duration of PROM [hrs.] & No. of Cases & Percentage \\
\hline $0-6 \mathrm{hrs}$ & 26 & $26 \%$ \\
\hline 7-12 hrs. & 43 & $43 \%$ \\
\hline 13-18 hrs. & 21 & $21 \%$ \\
\hline 19-24 hrs. & 18 & $18 \%$ \\
\hline$>24$ hrs. & 12 & $12 \%$ \\
\hline Total & 100 & $100 \%$ \\
\hline \multicolumn{3}{|c|}{ Table 3: Duration of PROM } \\
\hline
\end{tabular}

\begin{tabular}{|c|c|c|}
\hline Mode of Delivery & No. of Cases & Percentage \\
\hline Vaginal & 66 & $66 \%$ \\
\hline Instrumental & 13 & $13 \%$ \\
\hline Emergency LSCS & 14 & $14 \%$ \\
\hline Elective LSCS & 7 & $7 \%$ \\
\hline Total & $\mathbf{1 0 0}$ & $\mathbf{1 0 0} \%$ \\
\hline \multicolumn{2}{|c|}{ Table 4 Mode of Delivery }
\end{tabular}

\begin{tabular}{|c|c|c|}
\hline APGAR Score & No. of Cases & Percentage \\
$0-4$ & 2 & $2 \%$ \\
$5-8$ & 10 & $10 \%$ \\
$8-10$ & 88 & $88 \%$ \\
\hline NICU Admissions & 6 & $6 \%$ \\
Septicaemia & 4 & $4 \%$ \\
RDS & 3 & $3 \%$ \\
Birth Asphyxia & 2 & $2 \%$ \\
Perinatal Death & Table 5: Perinatal Outcome \\
\hline \multicolumn{2}{|c|}{} \\
\hline
\end{tabular}

\begin{tabular}{|c|c|c|}
\hline Complication & No. of Cases & Percentage \\
\hline Septicaemic Shock & 2 & $2 \%$ \\
\hline Wound Infection & 8 & $8 \%$ \\
\hline Fever & 12 & $12 \%$ \\
\hline Abruption & 4 & $4 \%$ \\
\hline \multicolumn{2}{|c|}{ Table 6: Maternal Morbidity } \\
\hline
\end{tabular}

\begin{tabular}{|c|c|c|}
\hline Organism & No. of Cases & Percentage \\
\hline Staphylococcus & 20 & $20 \%$ \\
\hline Streptococcus & 4 & $4 \%$ \\
\hline Klebsiella & 1 & $1 \%$ \\
\hline Pseudomonas & 8 & $8 \%$ \\
\hline Sterile & 67 & $67 \%$ \\
\hline \multicolumn{2}{|c|}{ Table 7: Organism on Culture } \\
\hline
\end{tabular}

\section{DISCUSSION}

M Gandhi et al[5] from Gujarat analysed 384 cases of PROM giving incidence of $5.2 \%$. Emechebe $\mathrm{C}$ et al[6] the incidence of prelabour rupture of membranes constituted $6.38 \%$ of all antenatal admissions. The incidence of term PROM in East China is approximately $12.5 \% .{ }^{[7]} \mathrm{M}$ Shah et al[8] in their study, the incidence of PROM was $7.86 \%$. The incidence of PROM in the present study was $1.2 \%$.

In a study by Emechebe $\mathrm{C}$ et al[6] most patients 63 $(32.8 \%)$ were in $25-29$ years age group and nulliparous 53 $(27.60 \%)$. In the present study, the incidence of PROM was highest in age group 20-29 years 49 cases [49\%] and nulliparous 58 cases [58\%].

$\mathrm{M}$ Shah et al[8] in their study, the incidence among lower socioeconomic group was $(62 \%)$ higher than the incidence (10\%) among higher socioeconomic group. In the present study, PROM cases were higher in the below poverty line [BPL] group 76 cases [76\%].

In the present study, 88 cases [88\%] delivered within 24 hours comparable to study by Shah et al[8] and M Gandhi et 
al[5] with $79.2 \%$ cases and $92.5 \%$ cases respectively.

In a study by Emechebe $\mathrm{C}$ et al,[6] the majority of the patients $79(41.2 \%)$ had a previous history of PROM. However, $45(23.4 \%)$ of the patients had no recognised risk factor. M Shah et al[8] in their study, $17 \%$ of cases with PROM had history of one or more abortions in previous pregnancies, $20 \%$ cases had history of PROM in previous pregnancies, $10 \%$ cases had history of preterm delivery due to PROM. In 15 cases, history of coitus $48 \mathrm{hrs}$. prior to PROM was present and 21 cases had history of coitus 2 days to 2 weeks back. In majority of the cases, the cause for PROM was idiopathic (42\%). Anaemia (22\%), infections (13\%), cervical stitch (3\%), malpresentations (5\%), hydramnios (5\%) were implicated risk factors for PROM. In the present study in 33 cases [33\%], no risk factors were identified, previous history of $\mathrm{D}$ and $\mathrm{C}$ was present in 12 cases [12\%], cervical incompetence in 11 cases [11\%], h/o previous preterm in 9 cases [9\%], h/o previous PROM in 8 cases [8\%], recent coitus in 7 cases [7\%], malpresentations in 6 cases [6\%], UTI in 6 cases [6\%], hydramnios in 4 cases [4\%], and twins in 4 [4\%] cases.

M Shah et al[8] in their study, among 52 primigravidae, 27 delivered vaginally, 6 were delivered by ventouse or forceps and 19 were delivered by LSCS. Among 48 multigravidae, 34 delivered vaginally, 4 were delivered by assisted vaginal delivery and 10 cases by LSCS. In the study by Emechebe $\mathrm{C}$ et al[6] majority, 124 (64.6\%) had vaginal deliveries while 68 $(35.4 \%)$ of them had emergency caesarean deliveries. In the present study, vaginal delivery either spontaneous of forceps was seen in 79 cases [79\%]. The rate of LSCS [21\%] was not increased due to PROM comparable to $27 \%$ in Sita Ram Shresta et al study[9] and 30 by Gaikwad BH[10] Swati Pandey[11] showed 31\% rate of caesarean section in the study group and $12 \%$ in the control group. Rate of caesarean section was higher in the studies by Anjana Devi[12] and Singhal[13] and lower in the studies by Piya Ray ${ }^{[14]}$ and Kamala Jayram.[15]

M Gandhi et al[5] maternal morbidity was $3.12 \%$ and maternal mortality was $0.26 \%$. Neonatal morbidity was $3.38 \%$ and neonatal mortality was $2.86 \%$. In the present study, most common complication in the mother was fever in 12 cases [12\%] followed by wound infection in 8 cases [8\%]. Septicaemic shock was seen in 2 cases [2\%] and abruption in 4 cases [4\%]. Infectious morbidity was $22 \%$ and the cases belonged to PROM of more than 19 hours. Hexia Xia et al[7] patients in the PROM group had a higher incidence of Bacterial Vaginitis (BV), Chlamydia Trachomatis (CT) infection, postpartum haemorrhage, and caesarean section deliveries. Infants in the PROM group experienced higher rates of infection, asphyxia, and jaundice. M Shah et al[8] in their study, maternal complications included chorioamnionitis (4\%), puerperal fever (22\%), abruption placenta $(2 \%)$, and wound infection (Both abdominal and episiotomy) in $14 \%$ cases. 82 neonates were delivered with Apgar $>5$ at birth and 18 with Apgar $<5$ at birth. Common causes for perinatal morbidity included birth asphyxia (2\%), hyperbilirubinaemia (2\%), septicaemia (10\%), meningitis (1\%), and pneumonia (5\%). The causes for perinatal mortality included septicaemia (1\%), meningitis $(1 \%)$, and pneumonia (2\%) and birth asphyxia (1\%). David R Dowdy et al[16] reported incidence of perinatal mortality as 5\%. Gaikwad $\mathrm{BH}^{[10]}$ maternal morbidity was $23 \%$. In study by
Sanyal,[17] perinatal morbidity was $32 \%$ and mortality was $5 \%$; Kodkany ${ }^{[18]}$ perinatal morbidity was $39.8 \%$ among which birth asphyxia was responsible for $29.5 \%$. In Anjana Devi's study, ${ }^{[12]}$ perinatal mortality rate was $4.8 \%$. In Piya Ray's ${ }^{[14]}$ study, it was $2.5 \%$. Gaikwad BH[10] study perinatal morbidity was $28 \%$ and mortality rate was $3.0 \%$.

In the present study, there was 2 babies [2\%] with Apgar score $0-4,10$ babies [10\%] with Apgar score 5-8, and 88 babies [88\%] with Apgar score 8-10. The most common cause for NICU admission was septicaemia 6 cases [6\%]. In the study by $\mathrm{V}$. Revathi et al,[19] the incidence of perinatal mortality was $2 \%$ similar to the present study i.e. $2 \%$. The rate of maternal morbidity in the present study was $26 \%$. The commonest cause was febrile morbidity (12\%). The most common cause of maternal morbidity was puerperal sepsis. Infectious morbidity was $22 \%$ and the cases belonged to PROM of more than 19 hours. In 67 cases [67\%], culture was sterile and the most common bacteria isolated were Staphylococcus in 20 cases [20\%].

\section{CONCLUSION}

PROM is associated with increased maternal and perinatal complications especially when duration of PROM is more than 24 hours. Identifying known risk factors, proper counseling, and prompt treatment of infections either UTI or vaginal is mandatory. The use of appropriate antibiotic following high vaginal swab culture report further reduces the complications associated with PROM. Also, delivering the women within 24 hours is important and expectant management is to be avoided as precious time is lost when induction is delayed.

\section{REFERENCES}

1. Rinehart BK. Premature ruptured membranes. In: Rivlin ME, Martin RW, (Eds). Manual of clinical problems in obstetrics and gynaecology. $5^{\text {th }}$ edn. Lippincott Williams and Wilkins 2000;23:117-9.

2. Eleje GU, Ezebialu IU, Umeobika JC, et al. Prelabour rupture of membranes at term: a review of management in a healthcare institution. Afrimedic Journal 2010;1(2): 10-14.

3. ACOG practice bulletin No. 80: premature rupture of membranes. Clinical management guidelines for obstetrician-gynaecologists. Obstet Gynaecol 2007;109(4):1007-19.

4. Hannah ME, Hodnett ED, William A, et al. Prelabour rupture of the membranes at term, expectant management at the home or in the hospital. The Term PROM study group. Obstet Gynaecol J 2002;96(4):533-8.

5. Gandhi M, Shah F, Panchal C. Obstetric outcomes in Premature Rupture of Membrane (PROM). The Internet Journal of Gynaecology and Obstetrics 2012;16(2):1-5.

6. Emechebe CI, Njoku CO, Anachuna K, et al. Determinants and complications of Prelabour Rupture of Membranes (PROM) at the University of Calabar Teaching Hospital (UCTH), Calabar, Nigeria. Sch J App Med Sci 2015;3(5B): 1912-7.

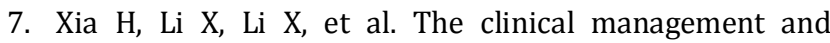
outcome of term premature rupture of membrane in East China: results from a retrospective multicenter study. Int J Clin Exp Med 2015;8(4):6212-7. 
8. Shah M, Sandesara P. Foetomaternal outcome in cases of Premature Rupture of Membrane (PROM) - a case control study. Gujarat Medical Journal 2011;66(1):36-8.

9. Shrestha SR, Sharma P. Foetal outcome of prelabour rupture of membranes. N J Obstet Gynaecol 2006;1(2): 19-24.

10. Gaikwad BH, Maskar RP. Study of maternal and perinatal outcome in premature rupture of membrane at term pregnancy. J Evolution Med Dent Sci 2016;5(37):2226-8.

11. Pandey S, Dave A, Bandi S. Maternal and foetal outcome in cases of PROM. Journal of Obstet and Gynaecology of India 2000;50:63.

12. Devi A, Rani R, Anjana D. Premature rupture of membranes-a clinical study. Journal of Obstet and Gynaecol of India 1996;46(1):63-8.

13. Singhal P, Singhal AK. Foetomaternal outcome in premature rupture of membranes. Obs and Gynae Today 2002;10:585

14. Priya R, Sikdar K, Das A, et al. Study of cases of chorioamniotics followed premature rupture of membranes. Journal of Obstet and Gynaecol of India 1997;47:136.
15. Jayaram VK, Sudha S. A study of PROM-management and outcome. Journal of Obstet and Gynaecol of India 2001;51:58-60.

16. Doody DR, Patterson MQ, Voigt LF, et al. Risk factors for recurrence of premature rupture of membranes. Paediatr Perinat Epidemiol 1997;11 (Suppl 1):96-106.

17. Sanyal MK, Mukherjee TN. Premature rupture of membranes, an assessment from a rural medical college of West Bengal. Journal of Obstetrics and Gynaecology on India 1990;40:623.

18. Kodkany, Telang. Premature rupture of membranes, a study of 100 cases. Journal of Obstet and Gynaecol of India 1991;41:492.

19. Revathi V, Sowjanya R, Lavanya S. Maternal and perinatal outcome in premature rupture of membranes at term. IOSR Journal of Dental and Medical Sciences 2015;14(4): 12-5. 